\title{
The relationship between the body wave and the local magnitudes for Himalayan earthquakes
}

\author{
M. P. Chhabra (*) R. K. S. Chauhan $(*)-$ H. N. Srivastava $(* *)-$ \\ H. M. Chaudhury.
}

Received on December 4 th, 1976

Sumiari. - Body wave $\left(M Y_{B}\right)$ and local magnitude $\left(M_{L}\right)$ were determined for earthquakes occurring within the epicentral range of 2 to $10^{\circ}$ from New Delhi during the years 1965-1974. The following relationships between them were found to hold good.

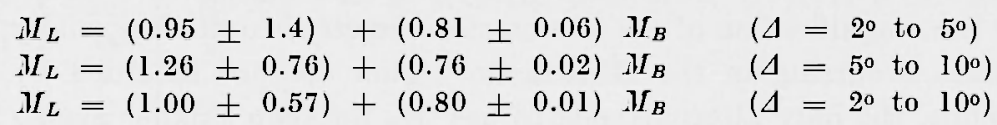

The regional variation of $\left(M_{C G S}-M_{B}\right)$ has been disenssed in terms of the focal mechanism and other parameters. It has been found that $\left(M_{C G S}-M_{B}\right)$ is positive near India-Nepal and Tibet border while elsewhere it is generally negative.

Riassunto. - Le magnitudo $M_{B}$ ed $M_{L}$ sono state determinate per quei terremoti avvenuti durante gli anni 1965-1974, entro un'area epicentrale compresa tra $2^{\circ}$ e $10^{\circ}$ da Nuova Delhi.

Le relazioni che legano $M_{B}$ ad $M_{L}$ sono risultate valide e sono le seguenti:

$\begin{array}{ll}M_{L}=(0.95 \pm 1.4)+(0.81 \pm 0.06) M_{B} & \left(\Delta=2^{\circ} \text { to } 5^{\circ}\right) \\ M_{L}=(1.26 \pm 0.76)+(0.76 \pm 0.02) M_{B} & \left(\Delta=5^{\circ} \text { to } 10^{\circ}\right) \\ M_{L}=(1.00 \pm 0.57)+(0.80 \pm 0.01) M_{B} & \left(\Delta=2^{\circ} \text { to } 10^{\circ}\right)\end{array}$

È stata discussa la variazione regionale $\left(M_{C G S}-M_{B}\right)$ basandosi sul meceanismo focale ed altri parametri.

La differenza suddetta ha valore positivo al confine fra India - Nepal e Tibet, mentre altrove risulta generalmente negativa.

$\left(^{*}\right)$ Geophysies Department, Indian School of Mines, Dhanbad, India.

(**) India Meteorological Department, Lodi Road, New Delli. 3, India. 


\section{INTRODUCTION}

The magnitude scales deriver from body waves and surface waves have been widely accepted after the installation of world wide seismograph system. However while using them for earthquakes occurring within the epicentral distance of ten degrees, several difficulties are encountered. In particular, surface waves of $20 \pm 2$ seconds period are rarely developed within this epicentral range to allow a computation of $M_{S}$ (surface wave magnitude). On the other hand, the use of the body wave magnitude, $M_{B}$ has been recommended for epicentral distances larger than 5 degrees. The determination of $M_{B}$ is difficult when the initial motion within a few cycles of the onset of $P$-waves is disturbed due to the complexities of the crustal structure as generally observed for the Himalayan earthquakes. Also, $M_{b}$ cannot be calculated for strong earthquakes, which render the record white.

For earthquakes occurring within $600 \mathrm{~km}$, the local magnitude, $M_{L}$ first derived by Richter for southern California based on the records of standard Wood Anderson Seismographs is generally used. Since however the magnification of the torsion seismometer is quite low, many earthquakes occurring in the Himalayan region are not recorded by them. Thus, the only alternative is to use $M_{B}$ for such smaller events inspite of its limitations within 5 degrees.

The object of this paper is to study the relationship between $M_{B}$ and $M_{L}$ for the epicentral distance range of 2 to 10 degrees so that the effects of using $M_{B}$ for $\Delta \leqslant 5$ and $M_{L} \geqslant 5.5$ may be brought out. In addition, the regional variation of the C.G.S. magnitude $M, M_{c c s}$ versus $M_{B}$ and $M_{L}$ has also been attempted in the light of the dominant focal mechanism in rlifferent regions.

\section{DATA AND ANALYSIS}

For this study, the records of all the earthquakes with foci within the crust which occurred within the epicentral distance of 2 to 10 degrees from New Delhi were examined for the years 1965 to 1974 . A total of 150 earthquakes were selected out of which $M_{B}$ and $M_{L}$ both could be determined for 52 earthquakes only. Although the focal depth determination were available only upto 1973 from the Bulletin of the International Seismological Centre, we have inclucled those earth- 
THE RELATIONSHIP BETWEEN THE BODY WAVE ETC.

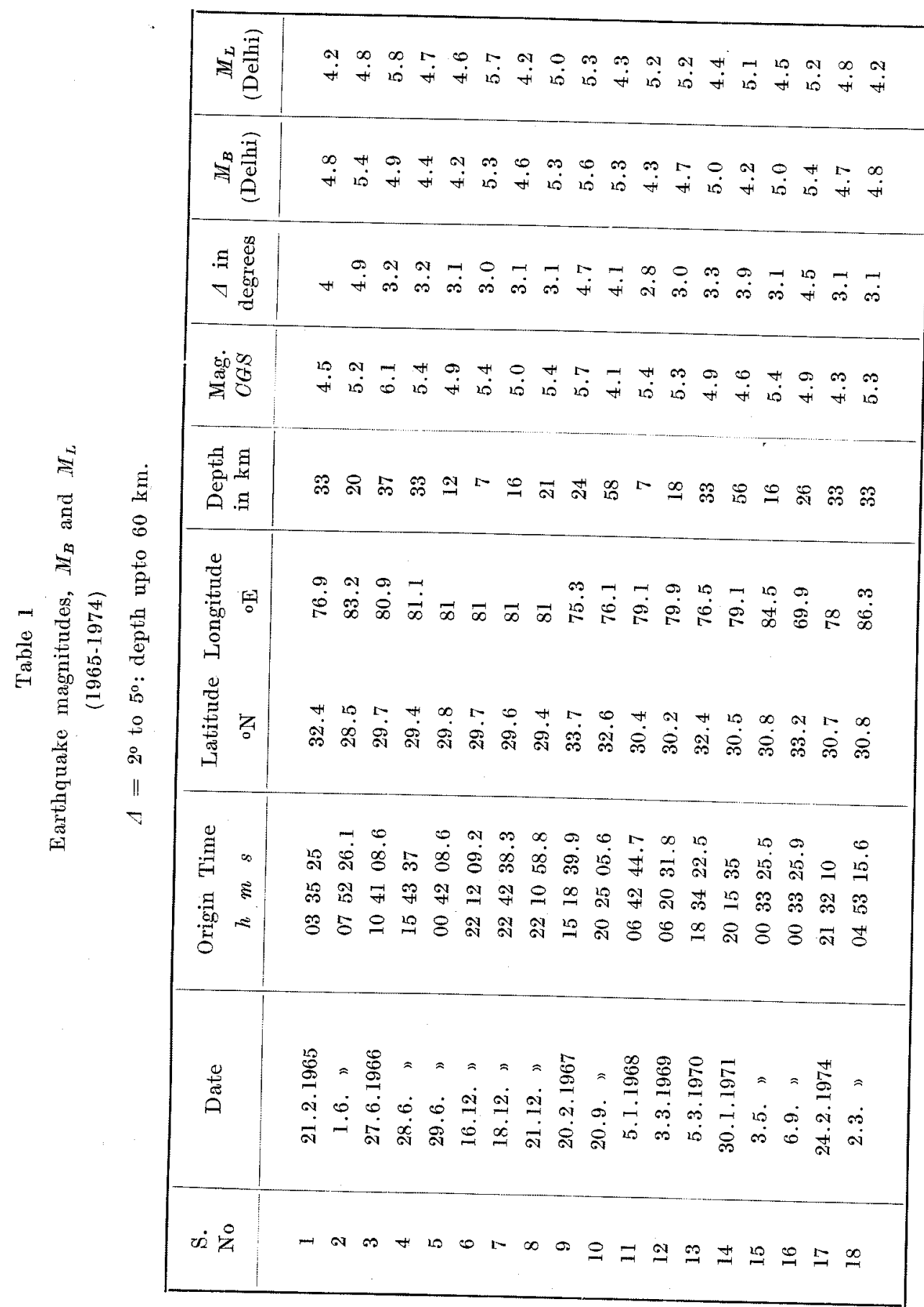


quakes occurring during 1974 for which reliable estimates of depths were available from Indian Seismological network. The data for the earthquakes is given in Table 1 .

The body wave magnitudes, $M_{B}$ were determined by using the Gutenberg Richter's relation, namely

$$
M_{B}=\log 10\left(\frac{A}{\pi T}\right)+Q
$$

Where $A_{\max }$ is one half of the through to peak trace amplitude in microns, $K$ is the peak magnification in thousands at the period to be read from the instrumental response characteristics of WWSSN Benioff system, $T$ the period of the waves within ( $1 \pm 0.3$ ) records of the onset of $P$ and $Q$ is the depth distance factor. It may be mentioned that the values of $Q$ have been tabulated from 2 degree onwards.

The local magnitude, $M_{L}$ was determined from the two horizontal component torsion seismometers aligned in north-south and east-west directions. Since the magnification of these instruments has been set at 1000 at Delhi Seismological Observatory, the average of the maximum double amplitudes measured in both the components (after allowing for the trace thickness and reducing to ground amplitude in microns) has been used to compute $M_{L}$. The plot of $M_{B}$ and $M_{L}$ is shown in fig. 1 where details will be discussed later.

\section{Results AND Discussion}

From the definition of $M_{B}$ and $M_{L}$ one may note that there is a very narrow range of epicentral distance around 5 degrees where both the magnitucle scales are theoretically valid. $\Lambda$ search for such earthquakes gave us meagre data (fig. 2). However in order to examine the eflects of using $M_{B}$ for $\Delta \leqslant 5$ and $M_{L} \geqslant 5.5$, two separate plots of $M_{B}$ and $M_{L}$ were made (fig. 1). The following relations have been found to hold good by least squares methods:

$$
\begin{aligned}
& M_{L}=(0.95 \pm 1.4)+(0.81 \pm 0.06) M_{B} \quad\left(\Delta=2^{\circ} \text { to } 5^{\circ}\right) \\
& M_{L}=(1.26 \pm 0.76)+(0.76 \pm 0.02) M_{B} \quad\left(\Delta=5^{\circ} \text { to } 10^{\circ}\right) \\
& M_{L}=(1.0 \pm 0.57)+(0.80 \pm 0.01) M_{B} \quad\left(\Delta=2^{\circ} \text { to } 10^{\circ}\right)
\end{aligned}
$$

The relationship between $M_{B}$ and $M_{L}$ has been deducted earlier [2] as

$$
M_{B}=1.7+0.8 M_{L}-0.01 M_{L}^{2}
$$




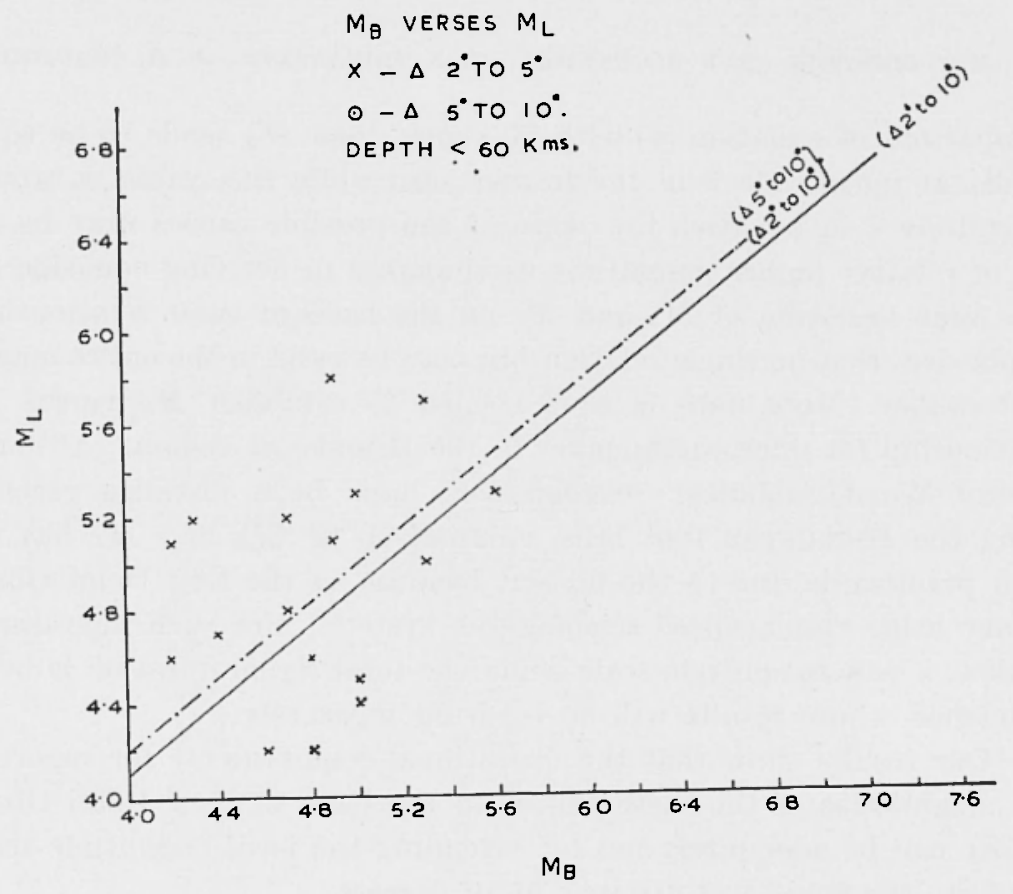

Fig. 1 - The relationship between $M_{B}$ and $M_{L}$ for earthquakes in Himalayas and neighbourhood.

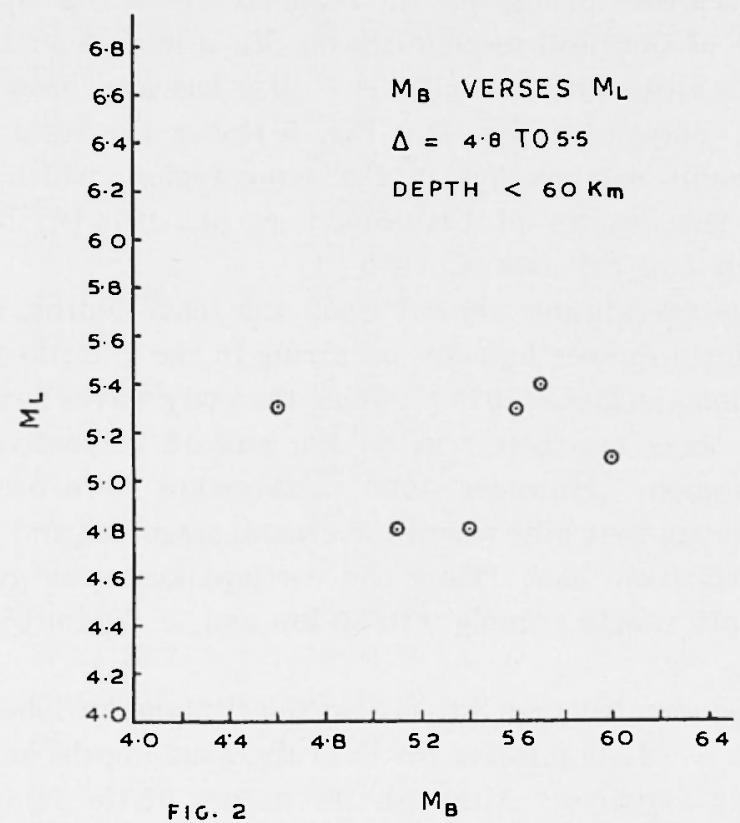

Fig. 2 - The variation of $M I_{B}$ and $M_{L}$ within the epicentral distance of 4.8 to $5.5^{\circ}$. 
Comparison of equation [4] with [5] shows that $M_{B}$ tends to be equal to $M_{L}$ at magnitule 5 in the former case while this value is around magnitude 7 in equation [5]. One of the possible causes may be the use of relative higher magnitude earthquakes in deriving equation [5]. The large variation of $M_{B}$ and $M_{L}$ on the basis of these relationships emphasizes that no single relationship may be valicl in the entire magnitude ranges. More data is thus needed to establish $M_{B}$ versus $M_{L}$ relationship for microearthquakes in the Fimalayan region. Although several Wood Anderson Seismometer's have been installed recently along the Himalayan foot hills, comparison of $M_{B}$ and $M_{L}$ has not been practicable due to the distant location of the New Delhi Observatory using standardised seismograph system. For such microearthquakes, a new magnitude scale using the total signal duration is being developed whose results will be reported separately.

Our results show that the operational requirements for reporting the magnitudes of the earthquakes on the basis of New Delhi Observatory can be adequately net by extending the local magnitude scale, $M_{L}$ upto the epicentral distance of 10 degrees.

The C.G.S. magnitude is the average of the body wave magnitudes reported by the standardized stations all over the world and thus takes into consideration the effects of the source mechanism. The difference of $M_{C \cdot S}-M_{B}$ thus brings out the regional effeets (fig. 3). Although the influence of the focal mechanism on $M_{L}$ is less understood mainly because of its restricted use, $\left(M_{C G S}-M_{L}\right.$ ) has also been plotted for the scale of comparison (fig. 4). Fig. 5 shows the focal mechanism solution of some earthquakes in the same region, which have been taken from the results of Chaudhury et al., 1974( $\left.{ }^{2}\right)$, Nowroozi ("), 1972, Tandon and Srivastava, $1975\left(^{7}\right)$.

Since the magnitudes depend upon the focal depths, it was desirable to separate the earthquakes oceuring in the granitic and basaltic layers. Tandon and Dube, $1973\left(^{6}\right)$, using the body waves have found the thickness of these two layers as $38 \mathrm{~km}$ and 13 respectively, for the Himalayan region. However some earthquakes have occurred close to the Himalayan foot hills where the crustal structure and the granitic layers are relatively less. Thus the earthquakes were grouped into two focal depth ranges namely 0 to $30 \mathrm{~km}$ and $\geqslant 30 \mathrm{~km}$ but restricted to the crust.

It may be seen from fig. 3 that near the Himalayan Tibet and Nepal border, $M_{c c s}-M_{B}$ is positive for both the focal depths and elsewhere it is generally negative. Although the nature of the faulting (fig. 5) 
Table 2

Earthquake magnitudes

$\Delta=5^{\circ}$ to $10^{\circ}$ : depth mpto $60 \mathrm{~km}$.

\begin{tabular}{|c|c|c|c|c|c|c|c|c|c|}
\hline $\begin{array}{l}\text { S. } \\
\text { No }\end{array}$ & Date & $\begin{array}{l}\text { Origin Time } \\
\qquad h m s\end{array}$ & $\begin{array}{l}\text { Latitude } \\
\text { oN }\end{array}$ & $\begin{array}{c}\text { Longitude } \\
\text { oE }\end{array}$ & $\begin{array}{l}\text { Deptlı } \\
\text { in } \mathrm{km}\end{array}$ & $\begin{array}{l}\text { Mag. } \\
\text { CoGis }\end{array}$ & $\begin{array}{l}1 \text { in } \\
\text { degrees }\end{array}$ & $\begin{array}{c}M_{B} \\
\text { (1)ellii) }\end{array}$ & $\begin{array}{c}M I_{L} \\
\text { (Delhi) }\end{array}$ \\
\hline 1 & 12.1 .1965 & 133224 & 27.6 & 88 & 23 & 6.1 & 9.4 & 6.6 & 6.2 \\
\hline 2 & 29.1 . & 20.06602 .4 & 35.6 & 73.6 & 41 & 5.7 & 10.0 & 5.7 & 5.6 \\
\hline 3 & $17.6 . " 1$ & $201+48.6$ & 32 & 87.8 & 15 & 5.4 & 9.7 & 5.7 & 5.7 \\
\hline 4 & 11.1 .19606 & $09 \quad 12 \quad 59.3$ & 34 & 72 & 36 & 5.4 & 9.1 & 5.7 & 5.6 \\
\hline 5 & $24.1 . "$ & 072307.6 & 29.9 & 69.7 & 26 & 5.8 & 6.7 & 6.2 & 6.5 \\
\hline 6 & 24.1 . " & 153248.1 & 29.9 & 69.8 & 14 & 5.3 & 6.4 & 53 & 5.4 \\
\hline 7 & $02.2 . "$ & 092007.5 & 33.9 & 73 & 37 & 5.3 & 8.3 & 5.7 & 5.7 \\
\hline 8 & 09.2. & $08 \quad 22 \quad 17.9$ & 29.8 & 69.8 & 16 & 5.2 & 8.7 & 5.8 & 5.9 \\
\hline 9 & 13.2." & $1909 \quad 47.4$ & 29.8 & 69.7 & 9 & 5.1 & 8.7 & 5.8 & 6.3 \\
\hline 10 & 17.2. & $1826 \quad 17.7$ & 29.9 & 69.8 & 40 & 4.4 & 8.7 & 6.5 & 5.6 \\
\hline 11 & $04.3 . "$ & 060105 & 30.0 & 70.0 & 33 & 4.4 & 8.4 & 5.8 & 6.0 \\
\hline 12 & 06.4. & 015151.8 & 35 & 73 & 54 & 5.1 & 9.3 & 6.4 & 6.1 \\
\hline 13 & $01.8 . "$ & 190955.1 & 29.9 & 68.8 & 33 & 5.8 & 7.3 & 6.3 & 5.9 \\
\hline 14 & $02.8 . "$ & $0541 \quad 37.4$ & 30 & 68.8 & 32 & 5.2 & 7.5 & 5.9 & 5.5 \\
\hline 15 & 02.2 .1967 & $\begin{array}{llll}07 & 37 & 54.9\end{array}$ & 39.7 & 75.5 & 39 & 5.3 & 10.7 & 6.0 & 5.0 \\
\hline 16 & $30.5 . "$ & $18 \quad 56 \quad 28.7$ & 31.7 & 30.1 & 44 & 4.6 & 6.4 & 5.0 & 4.9 \\
\hline 17 & 11.2 .1968 & $20 \quad 38 \quad 29.4$ & 34.2 & 78.6 & 44 & 5.1 & 5.5 & 5.1 & 4.8 \\
\hline 18 & $03.3 . "$ & $\begin{array}{llll}09 & 31 & 20.2\end{array}$ & 34.7 & 72.3 & 43 & 5.2 & 7.1 & 5.4 & 5.3 \\
\hline 19 & 04.4. & $01+426.4$ & 24.6 & 60 & 33 & 5.0 & 10.3 & 5.6 & 5.7 \\
\hline 20 & 26.7. & $2048 \quad 07.2$ & 32.07 & 70.07 & 50 & 4.8 & 7.2 & 5.0 & 4.9 \\
\hline 21 & $26.6 . \quad)$ & $00 \quad 4613.8$ & 37.7 & 69.9 & 16 & 5.2 & 10.0 & 6.1 & 01.0 \\
\hline 22 & $18.11 . "$ & $05 \quad 0504.3$ & 33.1 & 71.1 & 41 & 5.3 & 6.8 & 5.6 & 5.1 \\
\hline 23 & 22.1 .1969 & $19+221.8$ & 32.2 & 70 & 23 & 4.7 & 7.1 & 5.8 & 5.2 \\
\hline 24 & $03.3 . "$ & $1+0300.5$ & 31 & 71.8 & 35 & 4.5 & 5.5 & 4.6 & 5.3 \\
\hline 25 & 10.4 .1970 & 102358.2 & 25.3 & 66.7 & 33 & 5.1 & 9.7 & 6.3 & 5.5 \\
\hline 26 & $12.5 . "$ & 220739.4 & 27.5 & 67.5 & 7 & 4.7 & 8.5 & 4.7 & 5.2 \\
\hline 27 & 14.8." & $00 \quad 36 \quad 34.5)$ & 31.2 & 74.3 & 44 & 5.2 & 5.2 & 5.7 & 5.4 \\
\hline 28 & 08.1 .1971 & $23 \quad 52 \quad 16.3$ & 29.1 & 69.1 & 19 & 5.2 & 7.1 & 5.7 & 5.8 \\
\hline 29 & $24.3 . " \prime$ & 133946.3 & 30.3 & 67.8 & 18 & 4.9 & 8.0 & 5.4 & 5.0 \\
\hline 30 & $21.12 . "$ & $0954 \quad 40$ & 35.7 & 73.4 & 15 & 5.7 & 10.0 & 6.2 & 61 \\
\hline 31 & 06.11 .1972 & $1056 \quad 14$ & 26.8 & 88.4 & 59 & 4.4 & 9.8 & 5.6 & 5.7 \\
\hline 32 & 20.1 .1973 & 123420 & 29.3 & 68.6 & 19 & 5.3 & 7.1 & 5.9 & 5.6 \\
\hline 33 & $2+.2 . "$ & 215704 & 26.7 & 60.3 & 48 & 4.2 & 9.2 & $(j .0$ & 5.2 \\
\hline 34 & 09.2 .1974 & $0407 \quad 37.7$ & 28.7 & (i9. 4 & 33 & 4.9 & 8.5 & 5.4 & 4.8 \\
\hline 35 & $07.4 . "$ & $1607+3.8$ & 32.0 & 69.7 & 44 & 4.8 & 9.6 & 4.8 & 5.3 \\
\hline 36 & $03.8 . "$ & $0408 \quad 13.9$ & 35.4 & 71.7 & 20 & 5.0 & 10.3 & 6.0 & 5.4 \\
\hline
\end{tabular}




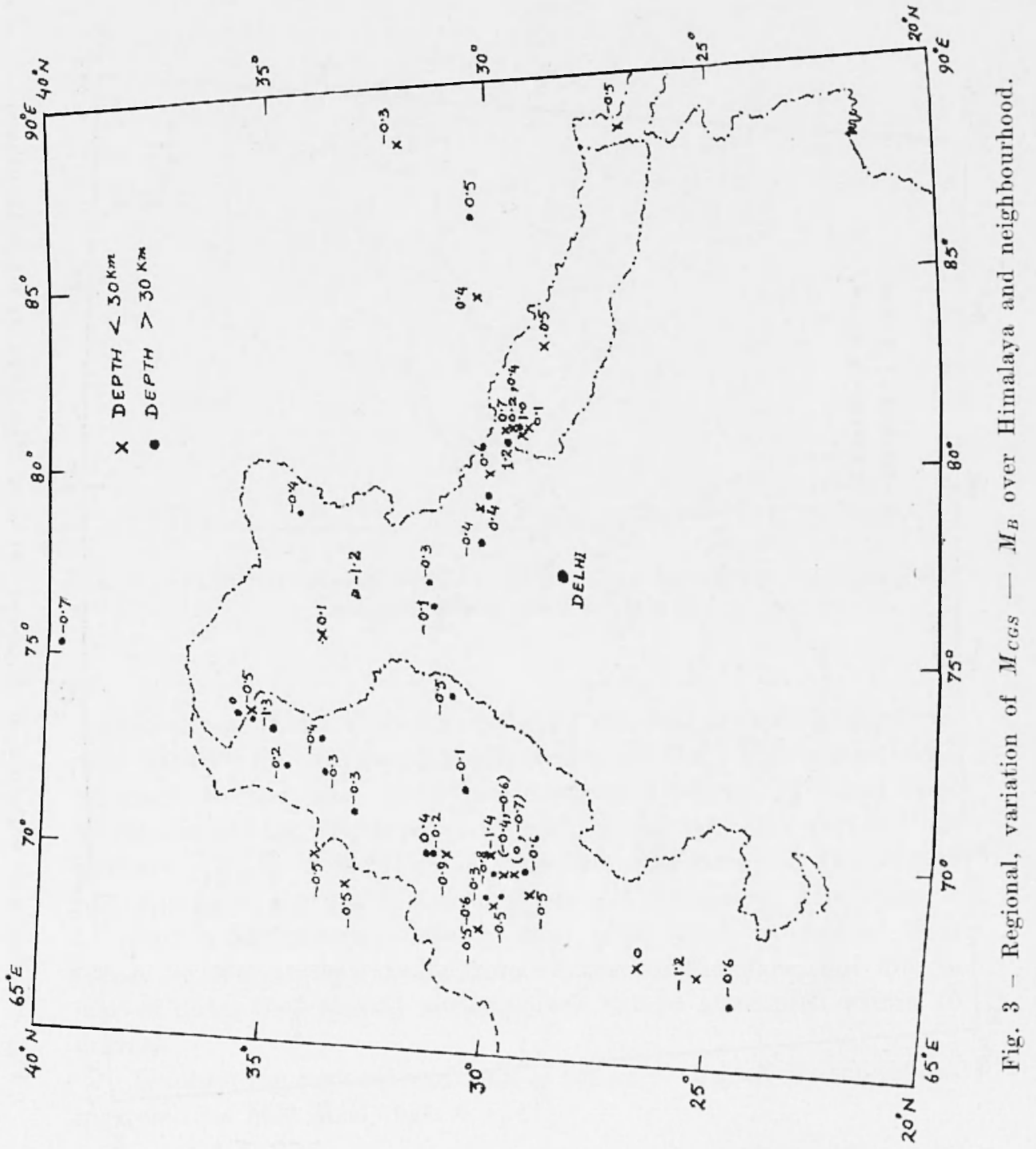




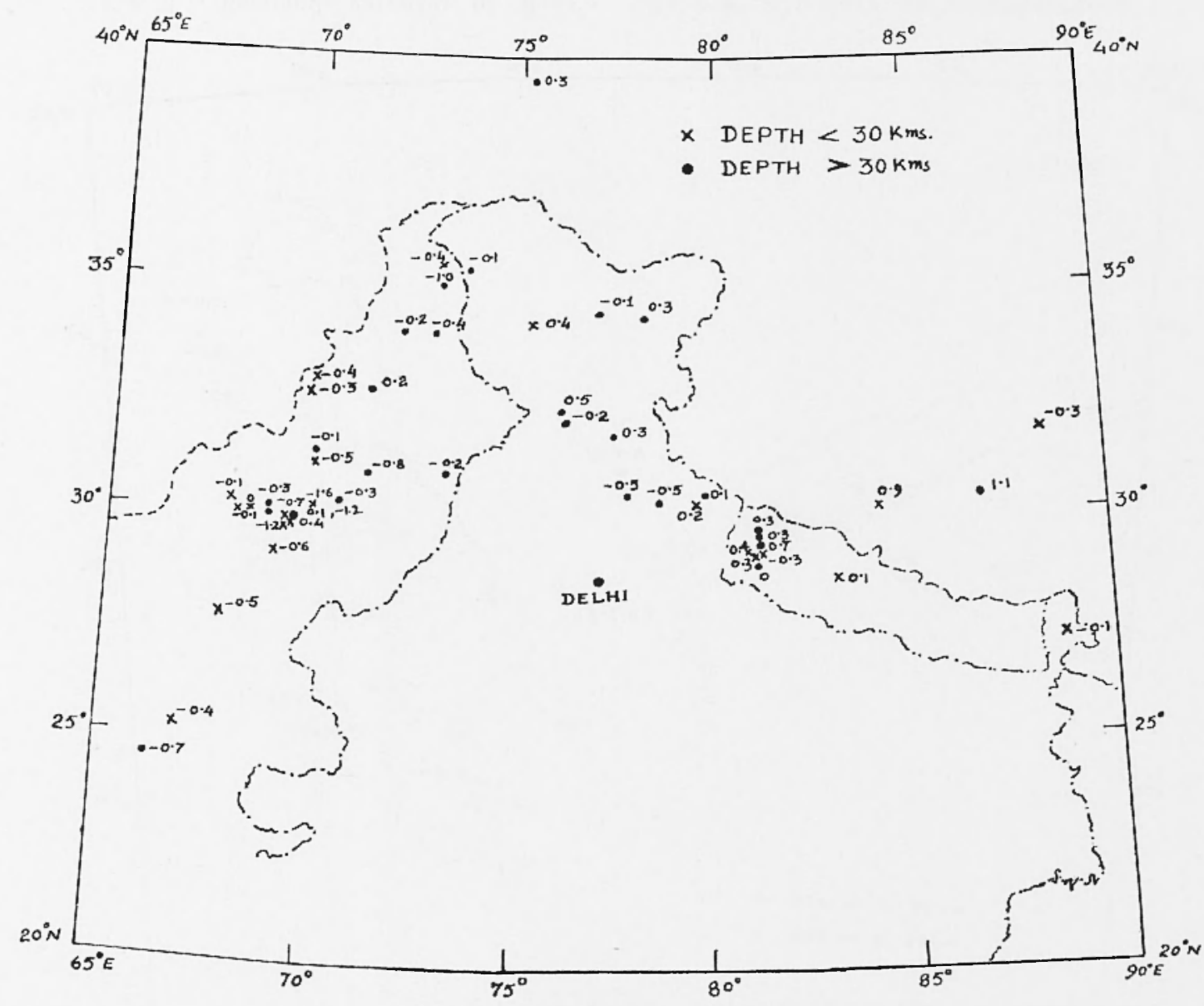

Fig. 4 - Regional variation of $M_{C G S}-M_{L}$ over Himalaya and neighbourhood. 


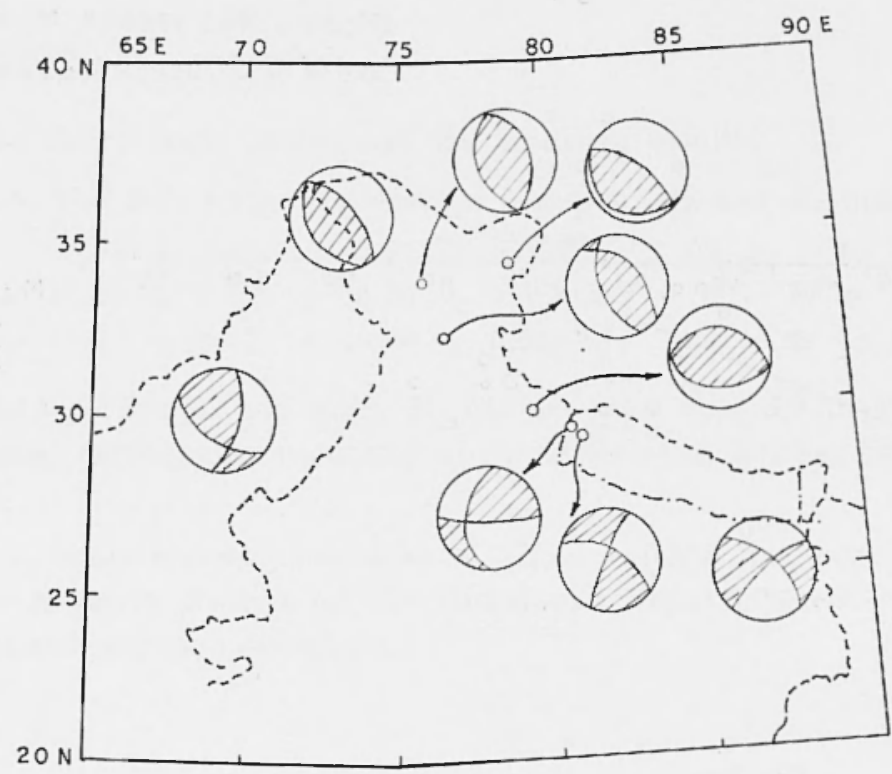

Fig. 5 - Focal mechanism solutions of some earthquakes in Himalaya and neighbourhood (see reference).

is generally of thrust type with different amounts of strike slip component in different regions, the orientation of the nodal planes with reference to the New Delhi Seismological Observatory could thus be responsible for this type of regional variations. The regional variation of $\left(M_{C G S}-M_{L}\right)$ is comparatively less marked (fig. 4) although this also gives a positive residual near the Himalayan trijunction.

Padmanabhamurthy, $1969\left(^{5}\right)$, has found negative residual from $\left(M_{C G S}-M_{L}\right)$ at New Delhi from shallow earthquakes, but due to lack of data, the regional variation was not be attempted within 10 degrees.

Ignoring the regional variation of $\left(M_{C G S}-M_{B}\right)$ or $M_{L}$ the following relations hold good (figs. $6 \mathrm{a}, \mathrm{b}$ ).

$$
\begin{aligned}
& \left(M_{C G S}-M_{B}\right)=(-2.2+0.3)+(0.38+0.02) M_{C G S} \\
& \left(M_{C G S}-M_{L}\right)=(-2.3+0.3)+(0.45+0.02) M_{C G S}
\end{aligned}
$$

Comparison of [6] with [7] shows that both the scales $M_{L}$ or $M_{B}$ can be used with almost same accuracy upto 10 degrees from New Delhi Observatory. 


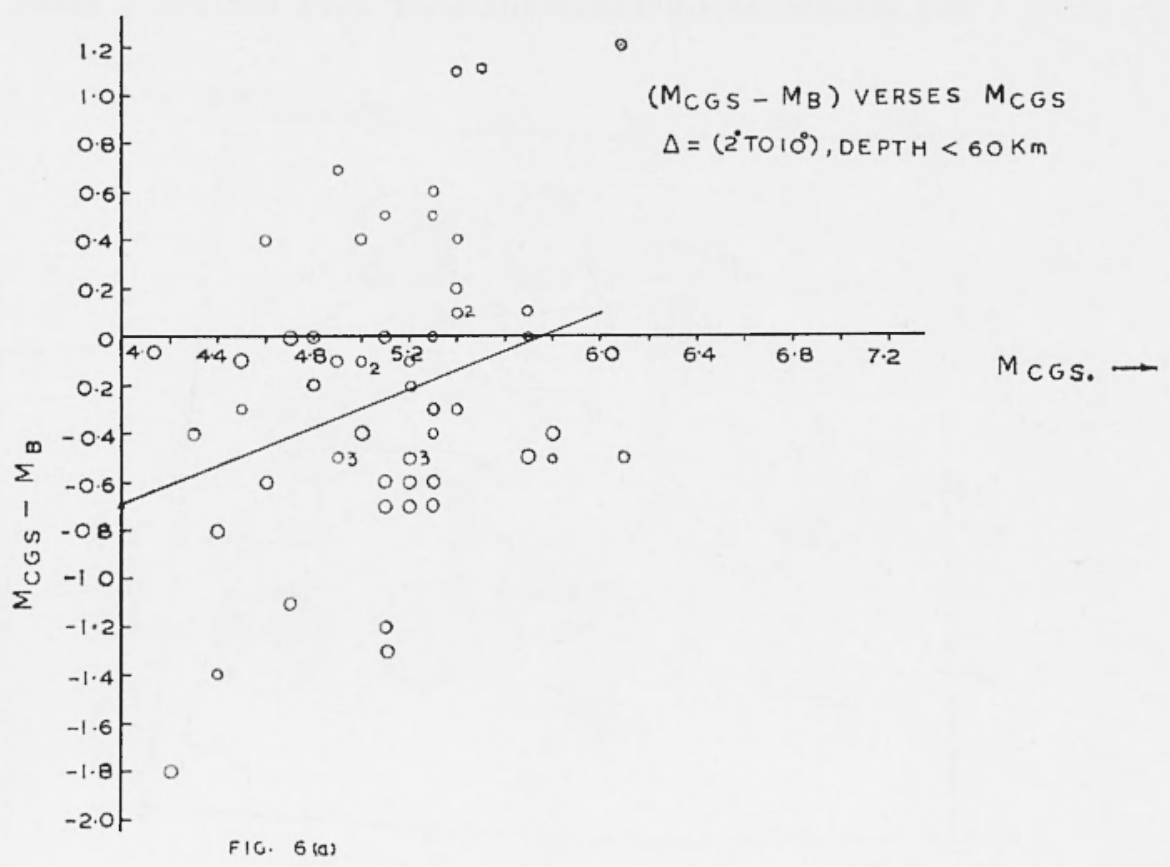

Figr. 6a - The relationship between $\left(M_{C G S}-M_{B}\right)$ and $M_{C G S}$

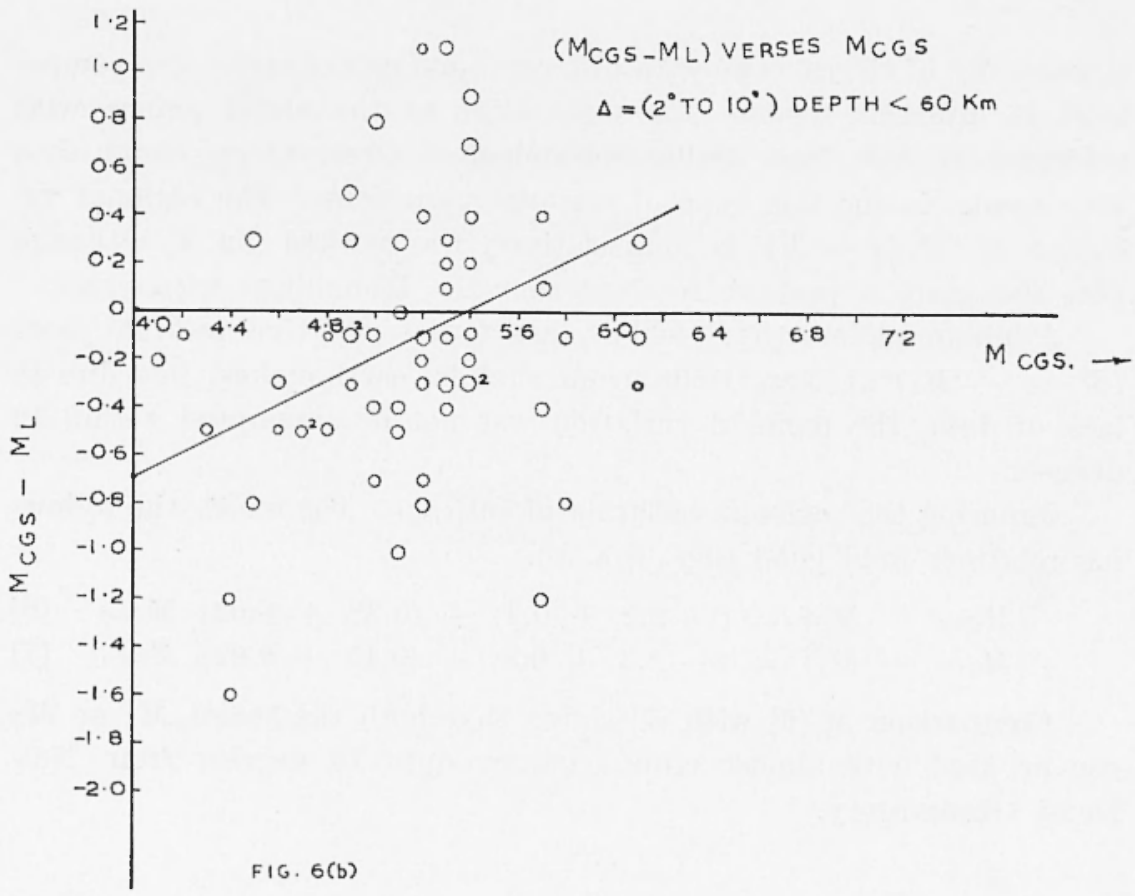

Fig. 6b - The relationship between $\left(H_{C G S}-M_{L}\right)$ and $M_{\text {izGS }}$. 


\section{CONCLLSION}

The above study brings out the following results:

1) - The following relationships between $M_{B}$ and $M_{L}$ hold goorl.

$$
\begin{aligned}
& M_{L}=(0.95 \pm 1.4)+(0.81 \pm 0.06) M_{B} \quad\left(\Delta=20 \text { to } 5^{\circ}\right) \\
& M_{L}=(1.26 \pm 0.76)+(0.76 \pm 0.02) M_{B} \quad\left(\Delta=5^{\circ} \text { to } 10^{\circ}\right) \\
& M_{L}=(1.0 \pm 0.57)+(0.80 \pm 0.01) M_{B} \quad\left(\Delta=2^{\circ} \text { to } 10^{\circ}\right)
\end{aligned}
$$

The local magnitude seale, $M_{L}$ can be used upto 10 degrees for the crustal earthquakes occurring in the Himalayan Kritluar Sulaiman ranges.

2) - Some regional variation of $\left(M_{C G S}-M_{B}\right)$ has been noted. $\left(M_{B}-M_{C G S}\right)$ is positive for the Himalayan Nepal Tibet tri-junction and general negative elsewhere.

\section{REFERENCEN}

(1) B\&тr, II., 1973. - Introduction to Seismology. p. 112.

(2) Chaudiury, H. M., Srivastava, H. N. and Subila Rao, J. V., 1974. Seismotectonies investigation of the Himalaya. "Himalayan (ieology", 4. pl. $481-491$.

(3) Gutenberg, B. and Ricuter, G. F., 1956. - Magnitude and energy of earthquakes, "Annali Geofis.", 9.

(4) Nowroosi, A. N., 1972. - Focal mechanism of earthquakes in Persia. Turkey, West Pakistan and Aghanistan and plate tectonics of the Middle East. "Bull Scism. Soc. Am.", 62, pl. 823-850.

(5) Padmanabianurtiy, B., I969. - Station magnitude Comnections for Shillong, Poona and New Delhi. "Ind. Jr. Met. Geopliysies", 20, p. 275.

(6) Tandon, A. N. and Dubk, R. K., 1973. - In: "Pure and Applied fieophy. sic's", 105.

(7) Tandon, A. N. and Srivastava, H. N., 1975. - Focal mechanism of some recent Himalayan earthquakes and regional plate tectonics. "Bull. Scism. Soc. Am., 65. pp. 963.970. 